This is the author's final, peer-reviewed manuscript as accepted for publication. The publisher-formatted version may be available through the publisher's web site or your institution's library.

\title{
Validation of molecular markers for new stem rust resistance genes in U.S. hard winter wheat
}

Amy N. Bernardo, Robert L. Bowden, Matthew N. Rouse, Maria S. Newcomb, David S. Marshall and Guihua Bai

\section{How to cite this manuscript}

If you make reference to this version of the manuscript, use the following information:

Bernardo, A. N., Bowden, R. L., Rouse, M. N., Newcomb, M. S., Marshall, D. S., \& Bai, G. (2013). Validation of molecular markers for new stem rust resistance genes in U.S. hard winter wheat. Retrieved from http://krex.ksu.edu

\section{Published Version Information}

Citation: Bernardo, A. N., Bowden, R. L., Rouse, M. N., Newcomb, M. S., Marshall, D. S., \& Bai, G. (2013). Validation of molecular markers for new stem rust resistance genes in U.S. hard winter wheat. Crop Science, 53(3), 755-764.

Copyright: (C) Crop Science Society of America

Digital Object Identifier (DOI): doi:10.2135/cropsci2012.07.0446

Publisher's Link: https://www.crops.org/publications/cs/articles/53/3/755

This item was retrieved from the K-State Research Exchange (K-REx), the institutional repository of Kansas State University. K-REx is available at http://krex.ksu.edu 


\section{Validation of molecular markers for new stem rust resistance genes in U.S. hard winter wheat}

Amy N. Bernardo, Robert L. Bowden, Matthew N. Rouse, Maria S. Newcomb, David S. Marshall and Guihua Bai*

Amy N. Bernardo, Dept. of Plant Pathology, Kansas State University, 4024 Throckmorton Hall, Manhattan, KS 66506; Guihua Bai and Robert L. Bowden, Hard Winter Wheat Genetics Research Unit, USDA-ARS, 4008 Throckmorton Hall, Manhattan, KS 66506; Matthew N. Rouse and Maria S. Newcomb, Cereal Disease Laboratory, USDA-ARS, 1551 Lindig Street, St. Paul, MN 55108; and David S. Marshall; USDA-ARS, Plant Science Research Unit, 3411 Gardner Hall, North Carolina State University, Raleigh, NC 27695.

*Corresponding author (guihua.bai@usda.ars.gov). Contribution number 12-381-J from the Kansas Agricultural Experiment Station. This project is partly funded by the National Research Initiative Competitive Grants CAP project 2011- 68002-30029 from the USDA National Institute of Food and Agriculture. Mention of trade names or commercial products in this article is solely for the purpose of providing specific information and does not imply recommendation or endorsement by the U.S. Department of Agriculture. USDA is an equal opportunity provider and employer. 


\section{ABSTRACT}

Stem rust, caused by Puccinia graminis f. sp. tritici (Pgt), is one of the most serious diseases of wheat (Triticum aestivum L.) worldwide. The discovery of new Pgt races in Africa, Ug99 and its variants, brings a new threat to global wheat production. Pyramiding several stem rust resistance genes into adapted varieties as opposed to breeding varieties with a single resistance gene is considered a more effective method to combat new races, but the success of gene pyramiding depends on the availability of molecular markers tightly linked to resistance genes. Markers for Ug99-effective genes, $\mathrm{Sr} 2$, Sr22, Sr26, Sr32, Sr35, Sr39, and Sr40, were evaluated for usefulness in marker-assisted selection (MAS) of hard winter wheat (HWW) using 10 resistance gene donor lines, 17 recently released U.S. HWW varieties or breeding lines, and 20 advanced introgression lines. Markers XcsIH81-BM and XcsIH81-AG for Sr22, Xsr26\#43 and XBE51879 for Sr26, Xbarc55 for Sr32, Xbarc51 for Sr35, Xrwg27 for Sr39, Xsr39\#22r for Sr40, and csSr2-derived single nucleotide polymorphism (SNP) marker for Sr2 are diagnostic for the set of HWW accessions evaluated in this study. These markers should be useful in marker-assisted pyramiding of stem rust resistance genes to develop HWW cultivars with multiple gene resistance against $\mathrm{Ug} 99$ races.

Abbreviations: Pgt, Puccinia graminis f. sp. tritici; MAS, marker-assisted selection; HWW, hard winter wheat, PCR, polymerase chain reaction; SSR, simple sequence repeats; R, resistant; MR, moderately resistant; MS, moderately susceptible; S, susceptible; SNP, single nucleotide polymorphism. 
Wheat stem rust, caused by Puccinia graminis f. sp. tritici (Pgt), is a devastating fungal disease of wheat. This pathogen infects leaves, stems, and glumes and reduces the supply of water and nutrients to the developing kernels, which results in shriveled grain (Roelfs et al., 1992; Schumann and Leonard, 2000). Yield loss due to stem rust was estimated at $20-50 \%$ in severe epidemics (Zadoks, 1963; Rees, 1972; Joshi and Palmer, 1973; Leonard, 2001). Wheat stem rust was a problem in the United States (U.S.) until the 1950s when barberry (Berberis vulgaris L.), its alternate host, was eradicated. Stem rust-resistant varieties were effectively deployed (Singh et al., 2006), and earlier-maturing wheat varieties reached advanced development stages prior to temperatures becoming warm enough for rapid stem rust increase (Marshall, 1989). For half a century, losses due to stem rust in the U. S. have been minimal (Leonard and Szabo, 2005); however, the recent discovery in Africa of Ug99, a virulent strain of the stem rust pathogen, brings a new threat to global wheat production (Singh et al., 2011).

Ug99, also known as race TTKSK, was first characterized from Uganda in 1999 (Pretorius et al., 2000). Ug99 caused severe infections in wheat known to have the stem rust resistance gene $\operatorname{Sr} 31$. Sr31 was transferred from rye to common wheat and had been effective for more than 30 years; Ug99 is the first race identified to be virulent to this widely deployed resistance gene (Pretorius et al., 2000). From Uganda, this stem rust race has migrated to Kenya, Ethiopia, Sudan, Yemen, and more recently to Iran (Singh et al., 2006; FAO, 2008). The race PTKST, with virulence to Sr24 and Sr31, and belonging to the Ug99 lineage was detected in South Africa in 2009 (Pretorius et al., 2010). New variants of Ug99 have been identified with virulence to extensively used resistance genes Sr24 and Sr36 (Jin and Singh, 2006; Singh et al., 2011). Because Sr24 and Sr36 were among the most important sources of resistance to stem rust 
in North American winter wheat (Jin and Singh, 2006), the great majority of U.S. winter wheat varieties are now genetically vulnerable to the Ug99 group of isolates.

Screening of worldwide wheat accessions has identified several stem rust resistance genes that remain effective against Ug99, including Sr2, Sr22, Sr26, Sr32, Sr35, Sr39, and Sr40 (Pretorius et al., 2000; Singh et al., 2011). These resistance genes were transferred to wheat from cultivated emmer and other wild relatives. Because the pathogen has demonstrated an ability to adapt to different resistance genes by gaining virulence, deployment of single new resistance genes is unlikely to be durable. A more effective method to combat Ug99 races would be to stack several new resistance genes into each new adapted variety (Leonard and Szabo, 2005; Mago et al., 2011). However, the success of gene pyramiding cannot rely on the availability of isolates of Ug99 and other new stem rust races that can differentiate the set of resistance genes to be stacked. It is not feasible to send all breeding materials to African stem rust nurseries or screen under containment in the U.S.

Molecular markers can predict the presence of a specific gene with very high probability without the need for disease evaluation, and thus aid the transfer of several resistance genes into adapted materials to pyramid several genes in one plant. Markers linked to resistance genes $\mathrm{Sr}$, Sr22, Sr26, Sr32, Sr35, Sr39, and Sr40 have been reported (Hayden et al., 2004; Khan et al., 2005; Mago et al., 2005; Babiker, 2006; Dundas et al., 2007; McNeil et al., 2008; Yu et al., 2009; Mago et al., 2009; Liu et al., 2010; Mago et al., 2010; Wu et al., 2009; Niu et al., 2011; Periyannan et al., 2011), but most of these markers were identified using a specific bi-parental mapping population, and levels of polymorphism for these markers may vary with parents. Genetic distances between markers and the resistance genes are also different among the genes. In addition, many of these markers were developed based on agarose gels, and subtle differences 
in amplicon size between accessions may be difficult to distinguish. This study aimed to 1) validate the DNA markers for Sr2, Sr22, Sr26, Sr32, Sr35, Sr39, and $\mathrm{Sr} 40$ in selected U.S. HWW varieties and breeding lines with different genetic backgrounds using a high-throughput genotyping system, and 2) evaluate the usefulness of the markers for those genes in MAS. This information will aid wheat breeders in selecting markers for use in MAS and gene pyramiding to enhance durability of stem rust resistance.

\section{MATERIALS AND METHODS}

\section{Plant materials}

The wheat materials used in this study were 10 stem rust resistant donor lines (positive controls), including Sr22Tb (Sr22), WA-1 (Sr26), CnsSr32As-k (Sr32), Mq(2)5*G2919K (Sr35), P8810B5B3A2A2 (Sr39), RL6088 (Sr40), CS-Hope DS 3B (Sr2), Hope (CI 8178; Sr2), 17 recently released HWW varieties or breeding lines, and 20 advanced stem rust resistance gene introgression breeding lines (Table 1). All resistance gene donors have been confirmed for rust resistance (Dundas et al., 2007; Jin et al., 2007; Yu et al., 2010) and all recently released cultivars do not contain any new alien resistance genes listed in this study according to their release documents. The cultivar 2174 was reported to be negative for Sr2 (Mago et al, 2011), Thunder CL was reported to be positive for Sr2 (Haley et al, 2009), but the status of the others is unknown.

\section{Stem rust evaluation}

Greenhouse evaluation of selected accessions for seedling host response against Pgt race TTKSK (Table 1) was conducted at the USDA Cereal Disease Laboratory in St. Paul, MN. Protocols for 
inoculum preparation, inoculation, incubation, and disease rating were as described by Jin and Singh (2006). Seedlings with infection type (IT) 0, ; 1, 2 or combinations thereof were considered resistant and those with an IT of 3 and/or 4 were classified as susceptible. Adult plant resistance was evaluated on Oct. 14, 2011 on the same set of materials in Njoro, Kenya, following the method described by Njau et al. (2010). Disease severity was assessed using the modified Cobb Scale (Peterson et al., 1948), and infection response was rated as R (resistant), MR (moderately resistant), MS (moderately susceptible), or S (susceptible) as described by Roelfs et al. (1992).

\section{Marker Analysis}

Genomic DNA was extracted from leaf tissue (bulk of 3-5 seedlings/line) following a CTAB protocol (Yu et al., 2008). One SNP marker for Sr2 and 24 SSR markers were evaluated (Table 2). A $10 \mu \mathrm{PCR}$ mix contained $1 \mathrm{X} \mathrm{NH} \mathrm{NH}_{4}$ buffer (Bioline, Randolph, MA), $2.5 \mathrm{mM} \mathrm{MgCl}, 0.2$ $\mathrm{mM}$ dNTPs, $50 \mathrm{nM}$ forward M13-tailed primer, $50 \mathrm{nM}$ M13-dye-labeled primer, $100 \mathrm{nM}$ reverse primer, 100 ng DNA, and 1 unit Taq polymerase (Promega, Madison, WI). PCR was carried out in a DNA Engine thermal cycler (Bio-Rad) using a touchdown program described by Sun et al. (2009). The thermal cycling conditions for SSR primer Wmc633 consisted of an initial denaturation at $95^{\circ} \mathrm{C}$ for $5 \mathrm{~min}$ followed by 40 cycles of $96^{\circ} \mathrm{C}(30 \mathrm{~s}), 48^{\circ} \mathrm{C}(1 \mathrm{~min})$ and $72^{\circ} \mathrm{C}(1$ min), with a final extension step of $5 \mathrm{~min}$ at $72^{\circ} \mathrm{C} . X s r 39 \# 22 r$ and $X r w g s$ markers were run based on conditions described by Mago et al. (2009) and Niu et al. (2011), respectively. For the Sr2 SNP marker, SNaPshot analysis was done following the protocol described by Bernardo et al. (2012). $\mathrm{Sr} 2 \mathrm{PCR}$ was done at $58^{\circ} \mathrm{C}$ annealing temperature and single base extension at $56^{\circ} \mathrm{C}$. PCR products were mixed with Hi-Di formamide and GeneScan 120, 500, or 1200 Liz size 
standard (Applied Biosystems, Foster City, CA), depending on the expected fragment sizes of PCR. Electrophoresis was done on a 3730 DNA Analyzer (Applied Biosystems, Foster City, CA), and amplification products were scored using GeneMarker software (Soft Genetics, State College, PA). All band/peak sizes mentioned herein include the M13 tail added to each forward SSR primer during primer synthesis and one of the following dyes incorporated during the PCR reaction: 6-FAM, VIC, PET or NED (Applied Biosystems, Foster City, CA).

\section{RESULTS}

\section{Markers for Sr22}

$\mathrm{Sr} 22 \mathrm{~Tb}$ is the donor of Sr22 and together with accessions U5615-98-120-2 and U5616-20-154-7 were used as positive controls for $\mathrm{Sr} 22$. Sr22 $\mathrm{Tb}$ contains a $\mathrm{T}$. boeoticum fragment that carries the Sr22 gene in chromosome 7AL (The, 1973). Four markers linked to Sr22, Xcfa2123, Xwmc633, XcsIH81-BM, and XcsIH81-AG (Khan et al., 2005; Olson et al., 2010; Periyannan et al., 2011), were tested. Marker XcsIH81-BM amplified a 257bp amplicon from the 7AL segment of $T$. boeoticum in the controls and three other resistant accessions (Table 1 and Supplementary Table 1), whereas XcsIH81-AG amplified a 385bp amplicon from the 7AL corresponding segment of $T$. aestivum which is present in all susceptible accessions but not in the resistant accessions (null allele), suggesting that this marker is diagnostic for Sr22. These two markers can be used together as co-dominant markers for Sr22. For marker Xcfa2123, the expected fragment size linked to $\operatorname{Sr} 22$ is $254 \mathrm{bp}$, and it showed up in all five resistant accessions except U5615-98-120-2 and one (U5941-1-6) of the 41 Sr22 susceptible accessions. This marker also did not amplify (null allele) in 18 accessions without Sr22. Marker Xwmc633 amplified a 135bp fragment in the Sr22 controls and all other Sr22-carrying accessions, and a 178bp fragment in non-Sr22-carrying 
accessions. Three non-Sr22 genotypes also amplified the 135bp fragment observed in Sr22 positive accessions in addition to the $178 \mathrm{bp}$ fragment, but the peak height of the $135 \mathrm{bp}$ fragment was at least seven times smaller than that of the $178 \mathrm{bp}$ band.

\section{Markers for Sr26}

The Sr26 resistance gene was introgressed from Thinopyrum ponticum to chromosome 6AL of wheat accession WA-1 (Dundas et al., 2007). Two markers were evaluated for Sr26 (Mago et al., 2005; Liu et al., 2010). Marker Xsr26\#43 amplified a 233bp fragment from WA-1, and an amplicon did not appear (null allele) in the other accessions tested. In contrast, the susceptible marker XBE51879 amplified a 328bp fragment from all non-Sr26 accessions and a null allele in the positive control. Thus, a combination of these two dominant markers can be used as a codominant diagnostic marker for Sr26.

\section{Markers for Sr32}

CnsSr32As-k (which is probably the same line as C77.19 produced by E.R. Sears) carries $\mathrm{Sr} 32$ on a translocation, which is a relatively large alien fragment in wheat, from Aegilops speltoides to chromosome 2B (McIntosh et al, 1995). Two markers have been developed for this gene: Xstm773 and Xbarc55 (Dundas et al., 2007; Yu et al., 2009). Xstm773 amplified a 209bp fragment in CnsSr32As, U5950-11-2, and CS-Hope DS 3B. CS-Hope DS 3B is an Sr2 resistant Chinese Spring accession with a 3B substitution from Hope; it does not carry any Ae. speltoides chromatin for Sr32 resistance. Because CnsSr32As and CS-Hope DS 3B are both Chinese Spring derivatives, the amplification of the 209bp fragment in both accessions implies that Xstm773 is actually tagging Chinese Spring and not the alien fragment from Ae. speltoides. The co-dominant marker Xbarc55 amplified a 128bp band in the positive control and two bands (128 and 141bp) in U5950-11-2, an accession that seems to be segregating for Sr32 based on stem rust evaluation 
using Ug99 (Table 1). Three other accessions that were initially thought to have Sr32 (U5926-28, U5926-3-4, and U5928-1-5) were negative for both Sr32 markers and susceptible to TTKSK. The most common Xbarc55 band sizes observed in non-Sr35 accessions were 141 and 149bp.

\section{Markers for Sr35}

The Sr35 resistance gene from T. monoccocum was transferred to chromosome 3AL of $\mathrm{Mq}(2) 5 * \mathrm{G} 2919 \mathrm{~K}$ (Zhang et al., 2010). Two markers, Xbarc51 and Xcfa2076, were reported to link to the gene (Babiker, 2009; Yu et al., 2009). Xbarc51 is a co-dominant marker and homozygous (236bp band) in the positive control, U5930-13-5, U5931-3-1, and U5951-5-2, and heterozygous in other accessions carrying Sr35 (U5930-11-3, U5932-2-4, and U5952-5-4). In addition to the 236bp band, a $327 \mathrm{bp}$ band was amplified in the latter accessions; the $327 \mathrm{bp}$ band was the most common band observed in non-Sr35 genotypes including recipient parents 'Duster' (PI 644016), 'Fuller' (PI 653521), and KS05HW14-1. Other band sizes observed in genotypes lacking Sr35 were 245, 249, and 325bp. Accessions U5930-13-5, U5931-3-1, and U5951-5-2 were resistant to Ug99 based on stem rust phenotypes, whereas the disease rating for accessions U5930-11-3, U5932-2-4, and U5952-5-4 ranged from $\mathrm{R}$ to $\mathrm{MS} / \mathrm{S}$ and appears to be heterogeneous and segregating for Sr35 (Table 1). Marker Xcfa2076 amplified a 207bp fragment in the donor parent and all other accessions with Sr35 except U5952-5-4. Xcfa2076 allele sizes observed in susceptible accessions were $88,143,150,155,160,211$, and 213bp. Moreover, no amplification (null allele) was observed in eight non-Sr35 samples, including 'Cedar', 'CJ', Sr22Tb, and P8810-B5B3A2A2.

\section{Markers for Sr39}

P8810-B5B3A2A2, a chromosome 2B recombinant containing an Ae. speltoides fragment (Friebe at al., 1996; Knox et al., 2000), is the donor for Sr39. Three markers were developed for 
this gene: Xsr39\#50s, Xsr39\#22r, and Xwmc474 (Mago et al., 2009; St. Amand, personal communication, 2011). Markers Xsr39\#50s and Xsr39\#22r are dominant for Sr39 susceptibility and resistance, respectively. The expected band size is $259 \mathrm{bp}$ for Xsr39\#50s and $818 \mathrm{bp}$ for Xsr39\#22r. CnsSr32As (Sr32) and RL6088 (Sr40) exhibited the same banding pattern as P8810B5B3A2A2 for both markers and is therefore a false positive for Sr39. Xwmc474 amplified a 171 bp band in all five accessions known to have Sr39 (P8810-B5B3A2A2, U5935-2-3, U59374-2, U5938-10-5, and U5954-1-5) based on stem rust evaluations (Table 1) and a smaller fragment (133-158bp) in non-Sr39 accessions. In addition, this marker also generated a 156 or 158bp amplicon in three Sr39-carrying accessions (U5937-4-2, U5938-10-5, and U5954-1-5), which suggests Sr39 heterozygosity. These genotyping results are consistent with stem rust phenotypic data where U5935-2-3 was clearly resistant, whereas U5937-4-2, U5938-10-5, and U5954-1-5 appear to be segregating (R-S disease rating) for Sr39.

Three new markers, Xrwgs27, Xrwgs28, and Xrwgs29, were recently developed for Sr39 using RWG accessions that carry a reduced-size Sr39 alien fragment in a wheat background (Niu et al., 2011). Xrwgs27 is a co-dominant marker and was able to differentiate Sr39-resistant accessions (673bp) from genotypes lacking $\operatorname{Sr} 39$ (426, 665, 666, 672, 677, and/or $683 \mathrm{bp})$ and heterozygotes (673bp plus another band). P8810-B5B3A2A2 and U5935-2-3 were resistant homozygotes based on Xrwgs27 marker data, whereas U5937-4-2, U5938-10-5, and U5954-1-5 were heterozygous; the Xrwgs27 marker data support the TTKSK bioassay results. The 673bp amplicon in Sr39-resistant accessions is only 1 bp bigger than that of CnsSr32As, a Chinese Spring accession with Sr32 in the same wheat chromosome 2B (Figure 1). Rwgs28 primers amplified 3-4 fragments with the 433bp band tagging the susceptible allele and 458bp band for the resistance allele; however, two accessions (CnsSr32As and RL6088) without the Sr39 gene 
also amplified the same banding pattern as the Sr39 donor P8810-B5B3A2A2. Xrwgs29 did not show polymorphism between accessions with or without Sr39 tested in this study. In addition, Xwmc474 developed for the larger alien fragment generated a 145bp amplicon in the RWG accessions with a shortened Sr39 alien segment instead of a $171 \mathrm{bp}$ band amplified in the accessions with a larger alien fragment, which suggests that this marker is located in an Ae. speltoides translocation that is now absent in the RWG accessions. This $145 \mathrm{bp}$ band is similar in size to that generated in the Chinese Spring derivatives CS-Hope DS 3B and WA-1; the RWG accessions have Chinese Spring background (Nui et al., 2011).

\section{Markers for $\operatorname{Sr} 40$}

Sr40 in RL6088 is located in chromosome 2BS and originated from T. timopheevii ssp. armeniacum (Dyck, 1992). RL6088 still contains a large alien segment, so linkage drag is expected. Six markers linked to Sr40 (Wu et al., 2009) were tested. Xgwm319 amplified a 195bp band not only in the donor line RL6088, but also in many non-Sr40-carrying genotypes such as 'Fuller', 'Lakin' (PI 617032), 'PostRock', KS05HW14-1, 'Thunder CL', and 'Duster'. Similarly, for marker Xwmc344, many accessions were false positives for Sr40, including 'PostRock', WA1, and Sr2 donor lines. The 154bp fragment amplified by Xwmc474 in RL6088 was also observed in the non-Sr40 accessions 'PostRock', 'Art', 'Aspen', and 'Thunder CL'. Xgwm374 generated a 232bp fragment in RL6088, U5942-10-1, U5947-1-3, and '2174' (GSTR 12101).

Because U5942-10-1 and U5947-1-3 have RL6088 and '2174' in their pedigrees, we cannot ascertain whether these accessions have $S r 40$ resistance based on this marker. Wmc477 primers amplified 1-3 bands. The expected band associated with the resistance allele of $S r 40$ is $182 \mathrm{bp}$. $\mathrm{Mq}(2) 5^{*} \mathrm{G} 2919 \mathrm{~K}$ and Sr22-carrying accessions Sr22Tb, U5924-10-1, and U5924-10-6 were false positive for this marker. In addition, scoring for this band is sometimes complicated by 
stutter bands in other fragments of bigger size. The last marker tested was Xwmc661, and it generated 1 - 4 bands in all tested accessions. A 190bp band was amplified in RL6088, but this band was absent in two other Sr40 accessions (U5942-10-1 and U5947-1-3).

Interestingly, Xsr39\#22r, a dominant marker developed for Sr39, showed good association with Sr40. This marker generated an 820bp band (Figure 2) in Sr40-carrying RL6088, U5942-10-1, and U5947-1-3, and an 818bp band or no band (null allele) in others including U5941-1-6, a non-Sr40 accession based on TTKSK bioassay. U5941-1-6 consistently showed the Fuller (recipient parent) alleles and not the expected Sr40 resistance alleles in all markers tested, so this line does not have $\mathrm{Sr} 40$ based on genotypic and phenotypic data.

\section{Markers for Sr2}

Unlike the other previously described resistance genes in this study, $\mathrm{Sr} 2$ is a non-race-specific adult plant resistance gene (Spielmeyer et al., 2003). Sr2 originated from T. turgidum var. dicoccum and was transferred to wheat chromosome 3BS (McFadden, 1930). Sr2 alone is not enough to protect wheat from losses due to stem rust, but it enhances resistance when combined with other stem rust resistance genes (Spielmeyer et al., 2003, Singh et al., 2011). Four markers, XcsSr2, X3B042G11, X3B028F08, and Xstm559TGAG were reported for the gene (Hayden et al., 2004; McNeil et al., 2008; Mago et al., 2011). Two wheat accessions, 'Hope' and CS-Hope DS 3B, are known to carry $\mathrm{Sr} 2$ and were used as positive controls. The expected X3B042G11 fragment size in $\mathrm{Sr} 2$ positive accessions is $172 \mathrm{bp}$, but non-Sr2 accessions have amplicons larger than $172 \mathrm{bp}$. The dominant marker $X 3 B 028 F 08$ amplified a 260bp fragment in non-Sr2 accessions and a null allele in those with Sr2. X3B042G11 and X3B028F08 genotyped 18 and 32 accessions as Sr2 false positive, respectively, including '2174', 'Aspen', 'Cedar', 'Duster', RL6088, and 'Tiger'. Marker Xstm559TGAG amplified several alleles and was difficult to score. 
The expected fragment sizes for this marker were 98 and 100bp for non-Sr2 accessions, and 100 and $102 \mathrm{bp}$ for $\mathrm{Sr} 2$ positive accessions; however, the amplification of stutter bands inherent in SSR markers and the tendency of Taq polymerase to add an additional nucleotide (usually A) at the 3'-end of PCR products (plus-A peaks) complicated data scoring (Figure 3). Non-Sr2 accessions 'Aspen', 'Hitch' (PI 655954), P8810-B5B3A2A2, 'Tiger', and U5947-1-3 showed the same banding pattern as the $\mathrm{Sr} 2$ positive controls and are therefore false positives. Marker XcsSr2 is a cleaved amplified polymorphic site (CAPS) marker (Mago at al., 2011) that we converted into a single nucleotide polymorphism (SNP) single base extension assay. Both positive controls and 'Thunder CL' showed the expected 'A' allele for $\mathrm{Sr} 2$, whereas 32 non-Sr2 accessions showed the ' $G$ ' allele, which indicates the absence of $\operatorname{Sr} 2$. The other 12 non-Sr2 accessions did not have an amplification product; among them were 'Art', 'CJ', 'Everest', 'PostRock', 'Tiger', Sr22Tb, WA-1, and CnsSr32As.

\section{DISCUSSION}

Markers for Ug99-effective resistance genes Sr2, Sr22, Sr26, Sr32, Sr35, Sr39, and Sr40 were evaluated for usefulness in MAS of HWW using wheat resistance gene donors, recently released U.S. HWW varieties, and advanced elite breeding lines. Markers that worked well across a wide range of accessions include XcsIH81-BM and XcsIH81-AG for Sr22, Xsr26\#43 and XBE51879 for Sr26, Xbarc55 for Sr32, Xbarc51 for Sr35, Xrwg27 for Sr39, Xsr39\#22r for Sr40 and XcsSr2SNP for Sr2. These markers showed a high level of polymorphism between the resistant 
accession(s) and a wide range of U.S. HWW breeding materials without the target genes, and thus are diagnostic markers for these genes.

In this study, some accessions had a mixed rating of $\mathrm{R}$ to $\mathrm{MS} / \mathrm{S}$ to TTKSK in both greenhouse and field conditions and were clearly segregating based on Ug99 stem rust evaluations. Co-dominant markers were able to detect these accessions as heterozygous. Xbarc51, Xbarc55, and Xrwg27 were good co-dominant markers for Sr35, Sr32, and Sr39, respectively. XcsIH81-BM coupled with XcsIH81-AG also can be used as co-dominant markers for Sr22, as well as markers Xsr26\#43 and XBE51879 for Sr26. These results mean that these codominant markers will be useful in screening for the presence of heterozygotes during early breeding generations. In contrast, the marker associated with Sr40 (Xsr39\#22r) is dominant and cannot distinguish heterozygotes from homozygotes. These results will help breeders to select parents for crosses, use the best markers to predict stem rust resistance genes in germplasm lines, and to stack several resistance genes in a single cultivar to improve durability of stem rust resistance in $\mathrm{HWW}$.

The resistance genes $\mathrm{Sr} 32, \mathrm{Sr} 39$, and $\mathrm{Sr} 40$ are all located in chromosome $2 \mathrm{~B}$, and each is probably in a non-recombining linkage block. $S r 40$ is a translocation from the G genome of $T$. timopheevii ssp. armeniacum, whereas Sr39 and Sr32 were derived from the S genome of Ae. speltoides. The $\mathrm{B}$ and $\mathrm{G}$ genomes of polyploid wheat are closely related to the $\mathrm{S}$ genome of Ae. speltoides (Dvorak and Zhang, 1990; Talbertet al., 1991), and the presence of a large alien translocation segment in Sr40 may explain why Xsr39\#22r can be used to select for Sr40. The target PCR product of Xsr39\#22r is $820 \mathrm{bp}$ for Sr40, which can be visualized easily in agarose gels if the samples being genotyped do not have Sr39; otherwise, the $818 \mathrm{bp}$ band for Sr39 cannot be distinguished from the $820 \mathrm{bp}$ fragment for $\mathrm{Sr} 40$ without a high-resolution system that can 
differentiate DNA fragments with a $2 \mathrm{bp}$ difference. Likewise, for Xrwg27 the amplified product in the Sr39 donor is only $1 \mathrm{bp}$ larger than that of the Sr32 donor (CnsSr32As); thus, a highresolution fragment analysis system and careful data scoring are necessary for the separation of Sr39 from Sr32 when Xrwg27 is used.

A CAPS marker for $\mathrm{Sr} 2$ was successfully converted into a SNP marker. This marker was the best marker for $\mathrm{Sr} 2$ based on our results. The disadvantage of this marker is that it behaves as a dominant marker in cases where some other resistance gene donors or some recently released HWW varieties are used as elite parents because this marker showed a null allele instead of a ' $G$ ' allele in these accessions. However, all accessions with the null allele in this study were $\mathrm{Sr} 2$ susceptible, which is consistent with the report by Mago et al. (2010), which found that most Australian lines also had the null allele. This result suggests that non-Sr2 accessions can have either the ' $G$ ' or null allele for this SNP marker, thus this marker is suitable for predicting Sr2.

Because most of the markers tested in this study were developed using a specific mapping population, not all of the markers worked well across the HWW accessions tested. Several markers showed polymorphism between the resistant accessions, and most, but not all, of the susceptible accessions. These markers will remain useful for a limited number of breeding populations if they are polymorphic between the parents. For example, Xgwm374 may be used as an alternate marker for Sr40 and will give reliable results as long as line '2174' is not in the pedigree of any parent because it is monomorphic between the Sr40 donor, RL6088, and '2174'. However, polymorphism was detected between RL6088 and other susceptible accessions tested in this study. Similarly, markers Xsr39\#50, Xsr39\#22r and Xrwg28 for Sr39 are also polymorphic between the Sr39 donor and other non-Sr39 accessions except two accessions with other resistance genes in 2B (CnSSr32As-k and RL6088). 
Although several markers were reported as tightly linked to target resistance genes in a specific population in previous studies, they were not diagnostic when in different backgrounds. Those markers gave false positives in different accessions without target resistance genes and are therefore not recommended for detecting the presence of target resistance genes and MAS. Those markers include X3B042G11, X3B028F08, and Xstm559TGAG for Sr2; Xcfa2123 for Sr22; Xstm773 for Sr32; Xrwg29 for Sr39; and Xwmc344, Xwmc477, Xgwm319, and Xwmc661 for $\operatorname{Sr} 40$.

In summary, closely linked markers to all stem rust resistance genes studied (Sr2, Sr22, Sr26, Sr32, Sr35, Sr39, and Sr40) were identified and validated. Validated markers for the seven genes worked well across the U.S. HWW accessions used in this study. These markers should be useful in stacking different resistance genes to develop wheat cultivars with durable stem rust resistance against Ug99 and its variants and in MAS of those resistance genes in HWW breeding materials. Marker-assisted analysis of these resistance genes is important to U.S. breeders because they cannot directly evaluate resistance to $\mathrm{Ug} 99$ and associated foreign races in their breeding. Using molecular markers in pyramiding 2-3 genes of $S r 24, S r 26, S r 31$, and $\operatorname{SrR}$ has been reported (Mago et al., 2011). Sr22, Sr26, and Sr35 confer resistance to Ug99 and other important races (Singh et al., 2011), and breeding efforts to pyramid these genes are already underway.

\section{ACKNOWLEDGMENTS}

The authors are indebted to Mike Pumphrey for providing the elite germplasm lines and Eric Olson for providing some controls and assistance with genotyping. 


\section{References}

Babiker, E., A.M.H. Ibrahim, Y. Yen, and J. Stein. 2009. Identification of a microsatellite marker associated with stem rust resistance gene Sr35 in wheat. Aust. J. Crop. Sci. 3:195-200.

Bernardo, A.N., H-X. Ma, D-D. Zhang and G-H. Bai. 2012. Single nucleotide polymorphism in wheat chromosome region harboring Fhb1 for Fusarium head blight resistance. Mol Breeding. 29:477-488.

Dundas, I.S., D.R. Anugrahwati, D.C. Verlin, R.F. Park, H.S. Bariana, R. Mago, and A.K.M.R. Islam. 2007. New sources of rust resistance from alien species: meliorating linked defects and discovery. Aust. J. Agric. Res. 58:545-549.

Dvorak, J., and H.B. Zhang. 1990. Variation in repeated nucleotide sequences sheds light on the origin of the wheat B and G genomes. Proc. Natl. Acad. Sci. USA. 87:9640-9644.

Dyck, P.L. 1992. Transfer of a gene for stem rust resistance from Triticum araraticum to hexaploid wheat. Genome. 35:788 Geno

Food and Agricultural Organization. 2008. Wheat killer detected in Iran. http://www.fao.org/newsroom/en/news/2008/1000805/index.html.

Friebe, B., J. Jiang, W.J. Raupp, R.A. McIntosh, and B.S. Gill. 1996. Characterization of wheatalien translocations conferring resistance to diseases and pests: Current status. Euphytica. 91:59tica

Haley, S.D., Johnson, J.J., Westra, P.H., Peairs, F.B., Stromberger, J.A., Heaton, E.E., Seifert, S.A., Kottke, R.A., Rudolph, J.B., Bai, G., Bowden, R.L., Chen, M.S., Chen, X., Jin, Y., Kolmer, J.A., and Seabourn, B.W. 2009. Registration of 'Thunder CL' wheat. J. Plant Registrations. 3:181-184.

Hayden, M.J., H. Kuchel, and K.J. Chalmers. 2004. Sequence tagged microsatellites for the Xgwm533 locus provide new diagnostic markers to select for the presence of stem rust resistance genes $\mathrm{Sr} 2$ in bread wheat (Triticum aestivum L.). Theor. Appl. Genet. 109:1641-1647.

Jin, Y., and R.P. Singh. 2006. Resistance in U.S. wheat to recent Eastern African isolates of Puccinia graminis f. sp. tritici with virulence to resistance gene Sr31. Plant Dis. 90:476480.

Jin, Y., R.P. Singh, R.W. Ward, R. Wanyera, M. Kinyua, P. Njau, T. Fetch, Z.A. Pretorius, and A. Yahyaoui. 2007. Characterization of seedling infection types and adult plant infection responses of monogenic stem rust resistance gene lines to race TTKS of Puccinia graminis f. sp. tritici. Plant Dis. 91:1096-1099. 
Joshi, L.M., and L.T. Palmer. 1973. Epidemiology of stem, leaf and stripe rusts of wheat in Northern India. Plant Dis. Reptr. 57:8-1.

Khan, R.R., H.S. Bariana, B.B. Dholakia, S.V. Naik, M.D. Lagu, A.J. Rathjen, and V.S. Gupta. 2005. Molecular mapping of stem and leaf rust resistance in wheat. Theor. Appl. Genet.111:846-850.

Knox, R.E., H.L. Campbell, R.M. DePauw, J.M. Clarke, and J.J. Gold. 2000. Registration of P8810.M. DePauw, J.M. Clark spring wheat germplasm with Lr35 leaf and Sr39 stem rust resistance. Crop Sci. 40:1512M. DeP

Leonard, K.J. 2001. Stem rust-future enemy? p. 119-146. In P.D. Peterson (ed.) Stem Rust of Wheat: from Ancient Enemy to Modern Foe. APS Press, St. Paul, MN.

Leonard, K.J., and L.J. Szabo. 2005. Stem rust of small grains and grasses caused by Puccinia graminis. Mol. Plant Pathol. 6:99-111.

Liu, S., L-X. Yu, R.P. Singh, Y. Jin, M.E. Sorrells, and J.A. Anderson. 2010. Diagnostic and codominant PCR markers for wheat stem rust resistance genes Sr25 and Sr26. Theor. Appl. Genet. 120:691-697.

Mago, R., H.S. Bariana, I.S. Dundas, W. Spielmeyer, G.J. Lawrence, A.J. Pryor, and J.G. Ellis. 2005. Development of PCR markers for the selection of wheat stem rust resistance genes Sr24 and Sr26 in diverse wheat germplasm. Theor. Appl. Genet. 111:496-504.

Mago, R., G. Brown-Guedira, S. Dreisigacker, J. Breen, Y. Jin, R. Singh, R. Appels, E. S. Lagudah, J. Ellis, and W. Spielmeyer. 2011. An accurate DNA marker assay for stem rust resistance gene Sr2 in wheat. Theor. Appl. Genet. 122:735-744.

Mago, R, J.G. Lawrence, and J.G. Ellis. 2011. The application of DNA marker and double haploid technology for stacking multiple stem rust resistance genes in wheat. Mol. Breed. 27:329-335.

Mago, R., P. Zhang, H.S. Bariana, D.C. Verlin, U.K. Bansal, J.G. Ellis, and I.S. Dundas. 2009. Development of wheat lines carrying stem rust resistance gene Sr39 with reduced Aegilops speltoides chromatin and simple PCR markers for marker-assisted selection. Theor. Appl. Genet. 119:1441-1450.

Marshall, D. 1989. National and International Breeding Programs and Deployment of Plant Germplasm: New Solutions or New Problems? p. 182-203 In M. J. Jeger (ed.) Spatial Components of Plant Disease Epidemics. Prentice-Hall.

McFadden, E.S. 1930. A successful transfer of emmer characters to vulgare wheat. J. Am. Soc. Agron. 22:1020-1034

McIntosh, R.A., Wellings, C.R., and Park, R.F. 1995. Wheat Rusts: An Atlas of Resistance Genes. CSIRO, Australia. 200 pp. 
McNeil, M.D., R. Kota, E. Paux, D. Dunn, R. McLean, C. Feuillet, D. Li, X. Kong, E. Lagudah, J.C. Zhang, J.Z. Jia, W. Spielmeyer, M. Bellgard, and R. Appels. 2008. BAC-derived markers for assaying the stem rust resistance gene, $S r 2$, in wheat breeding programs. Mol. Breed. 22:15-24.

Niu, Z., D.L. Klindworth, T.L. Friesen, S. Chao, Y. Jin, X. Cai, and S.S. Xu. 2011. Targeted introgression of a wheat stem rust resistance gene by DNA marker-assisted chromosome engineering. Theor. Appl. Genet. 187:1011-1021.

Njau, P. N., Y. Jin, J. Huerta-Espino, B. Keller, and R. P. Singh. 2010. Identification and evaluation of sources of resistance to stem rust race Ug99 in wheat. Plant Dis. 94:413419.

Olson, E.L., G. Brown-Guedira, D. Marshall, E. Stack, R.L. Bowden, Y. Jin, M. Rouse, and M.O. Pumphrey. 2010. Development of wheat lines having a small introgressed segment carrying stem rust resistance gene Sr22. Crop Sci. 50:1823-1830.

Periyannan, S. K., U.K. Bansal, H.S. Bariana, M. Pumphrey, and E.S. Lagudah. 2011. A robust molecular marker for the detection of shortened introgressed segment carrying the stem rust resistance gene Sr22 in common wheat. Theor. Appl. Genet. 122:1-7.

Peterson, R. F., A. B Campbell, and A. E. Hannah. 1948. A diagrammatic scale for estimating rust severity on leaves and stems of cereals. Can. J. Res. Sect. C. 26:496-500.

Pretorius, Z.A., C.M. Bender, B. Visser, and T. Terefe. 2010. First report of a Puccinia graminis f.sp. tritici race virulent to the Sr24 and Sr31 wheat stem rust resistance genes in South Africa. Plant Dis. 94:784.

Pretorius, Z.A., R.P. Singh, W.W. Wagoire, and T.A. Payne. 2000. Detection of virulence to wheat stem rust resistance gene Sr31 in Puccinia graminis f. sp. tritici in Uganda. Plant Dis. 84:203.

Rees, RG. 1972. Uredospore movement and observations on the epidemiology of wheat rusts in north-eastern Australia. Aust. J. Agric. Res.23:215-223

Roelfs, A.P., and R.P. Singh, E.E. Saari. 1992. Rust Diseases of Wheat: Concepts and methods of disease management. Mexico, D.F.: CIMMYT. 81 pages.

Schumann, G.L. and K.J. Leonard. 2000. Stem rust of wheat (black rust). In The Plant Health Instructor. DOI: 10.1094/PHI-I-2000-0721-01.

Singh, R.P., D.P. Hodson, J. Huerta-Espino, Y. Jin, S. Bhavani, P. Njau, S. Herrera-Foessel, P.K. Singh, S. Singh, and V. Govindan. 2011. The emergence of Ug99 races of stem rust fungus is a threat to world wheat production. Annu. Rev. Phytopathol. 49:13.1-13.17. 
Singh, R.P., D.P. Hodson, Y. Jin, J. Huerta-Espino, M.G. Kinyua, R. Wanyera, P. Njau, and R.W. Ward. 2006. Current status, likely migration and strategies to mitigate the threat to wheat production from race Ug99 (TTKS) of stem rust pathogen. CAB Rev. Perspect. Agric. Vet. Sci. Nutr. Nat. Res. 54:1-13.

Spielmeyer, W., P.J. Sharp, and E.S. Lagudah. 2003. Identification and validation of markers linked to broad-spectrum stem rust resistance gene $\mathrm{Sr} 2$ in wheat (Triticum aestivum L.). Crop Sci. 43:333-336.

Stakman, E. C., D. M. Stewart and W. Q. Loegering. 1962. Identification of physiologic races of Puccinia graminis var. tritici. U.S. Dep. Agric. Agric. Res. Serv. E-617.

Sun, X., G. Bai, and B. Carver. 2009. Molecular markers for wheat leaf rust resistance gene Lr41. Mol. Breeding. 23:311-321.

Talbert, L.E., G.M. Magyer, M. Lavin, T.K. Blake, and S.L. Moylan. 1991. Molecular evidence for the origin of the S-derived genomes of polyploid Triticum species. Am. J. Bot. 78:340-349.

The, T.T. 1973. Chromosome location of genes conditioning stem rust resistance transferred from diploid to hexaploid wheat. Nat. New Biol. 241:256.

Zadoks, J.C. 1963. Epidemiology of wheat rust in Europe. FAO Plant Protection Bull. 13:97108.

Wu, S., M. Pumphrey, and G. Bai. 2009. Molecular mapping of stem rust-resistance gene Sr40 in wheat. Crop. Sci. 49:1681-1686.

Yu, G., Q. Zhang, D.L. Klindworth, T.L. Friesen, R. Knox, Y. Jin, S. Zhong, X. Cai, and S.S. $\mathrm{Xu}$. 2010. Molecular and cytogenetic characterization of wheat introgression lines carrying the stem rust resistance gene Sr39. Crop Sci. 50: 1393-1400.

Yu, JB, GH Bai, WC Zhou, YH Dong, FL Kolb. 2008. Quantitative trait loci for Fusarium head blight resistance in a recombinant inbred population of Wangshuibai/Wheaton.

Phytopathology. 98:87-94.

Yu, L-X., Z. Abate, J.A. Anderson, U.K. Bansal, H.S. Bariana, S. Bhavani, J. Dubcovsky, E. S. Lagudah, S-X. Liu, PK Sambasivam R.P. Singh, and M.E. Sorrells. 2009. Developing and optimizing markers for stem rust resistance in wheat. In Borlaug Global Rust Initiative 2009 Technical Workshop. Cd. Obregon, Sonora, Mexico. March 17-20, 2009. 
Table 1. Wheat accessions, host responses to stem rust Pgt race TTKSK and marker results.

\begin{tabular}{|c|c|c|c|c|}
\hline Selection & Pedigree & Greenhouse $^{\mathrm{a}}$ & Field $^{b}$ & $\begin{array}{l}\text { Marker } \\
\text { Results }\end{array}$ \\
\hline CS-Hope DS 3B & Hope $(2 \mathrm{~B}) / *$ Chinese-Spring & $3+$ & & Sr2 (Control) \\
\hline Hope & Yaroslav-emmer/Marquis & $3+$ & & Sr2 (Control) \\
\hline $\mathrm{Sr} 22 \mathrm{~Tb}$ & Steinwedel*2//Spelmar*2/T. boeoticum G-21 & $2-$ & & Sr22 (Control) \\
\hline U5615-98-120-2 & $2174 / \mathrm{Sr} 22 \mathrm{~Tb}$ & $22-$ & & Sr22 (Control) \\
\hline U5616-20-154-7 & Lakin/Sr22Tb & $2-$ & & Sr22 (Control) \\
\hline WA-1 & Eagle/Chinese Spring Ph1ph1b/*6 Angas & & & Sr26 (Control) \\
\hline CnsSr32A.s. & Ae. speltoides and Chinese Spring & $1+^{\mathrm{d}}$ & & Sr32 (Control) \\
\hline $\mathrm{Mq}(2) 5 * \mathrm{G} 2919 \mathrm{~K}$ & Marquis*5/G2919K & $;^{\mathrm{d}}$ & & Sr35 (Control) \\
\hline P8810-B5B3A2A2 & HY366/ RL5711//2*HY366/3/3*HY366-BL31.RL5711 & 2 & & Sr39 (Control) \\
\hline RL6088 & RL6071*7/PGR6195 & $1^{\mathrm{d}}$ & & Sr40 (Control) \\
\hline 2174 & IL-71-5662/PL-145//PIONEER-2165 & $3+$ & & None \\
\hline Armour & B1551-WH/KS94U326 & 2 & & None \\
\hline Art & Jagger/W94-244-132 & 4 & & None \\
\hline Aspen & TAM302/B1551W & & & None \\
\hline Billings & Erythrospermum-2755-91/Odisseya(N-566)//OK-94-P-597 & 2 & & None \\
\hline Cedar & TAM302/B1551W & & & None \\
\hline CJ & W-99-188-S-1/BC-950814-1-1 & & & None \\
\hline CO01W172 & 96HW100-5/96HW114 & $3+$ & & None \\
\hline Duster & W0405/NE78488//W7469C/TX81V6187 & $3+$ & & None \\
\hline Everest & $\begin{array}{l}\text { HBK1064-3/Betty 'S'//VBF0589-1/ } \\
\text { IL89-6483 (Pioneer9021L//Roland/IL77-2656) }\end{array}$ & & & None \\
\hline Fuller & Jagger/(Line-USDA-ARS) Lr-genes_from_wild_relatives & 4 & & None \\
\hline Hitch & G53/3/Abilene/G1113//Kar192/4/Jagger/5/KS89180B & & & None \\
\hline KS05HW14-1 & $\begin{array}{l}\text { KS98HW452(KS91H153/KS93HW255)/CO960293//KS92070 } \\
\text { 9B-5-2(T67/X84W063-9-45//K92) }\end{array}$ & 4 & $50 \mathrm{~S}$ & None \\
\hline Lakin & Arlin/KS89H130 & $3+$ & & None \\
\hline PostRock & Ogallala/KSU94U261//Jagger & $4 / 3+$ & & None \\
\hline
\end{tabular}




\begin{tabular}{|c|c|c|c|c|}
\hline Thunder CL & KS01-5539/CO99W165 & $3+$ & & Sr2 \\
\hline Tiger & $\begin{array}{l}\text { KS98HW518(93HW91/93HW255)//KS98H245(IKE/TA2460// } \\
\text { *3T200)/Trego }\end{array}$ & & & None \\
\hline U5924-10-1 & Fuller*2//Sr22Tb/2*2174 & 2 & TrR & Sr22 \\
\hline U5924-10-6 & Fuller*2//Sr22Tb/2*2174 & $22-$ & 5R & Sr22 \\
\hline U5926-2-8 & Duster*2//CnsSr32As/2*2174 & $3+$ & $45 \mathrm{MSS}$ & Non-Sr32 \\
\hline U5926-3-4 & Duster*2//CnsSr32As/2*2174 & $3+$ & 30MSS & Non-Sr32 \\
\hline U5928-1-5 & Fuller*2//CnsSr32As/2*2174 & $3+$ & $55 \mathrm{~S}$ & Non-Sr32 \\
\hline U5930-11-3 & Duster*2//Mq(2)5*G2919K(Sr35)/2*2174 & $0 / 3+$ & $\begin{array}{l}5 \mathrm{R} / 30 \mathrm{MS} \\
\mathrm{S}\end{array}$ & $\mathrm{Sr} 35^{e}$ \\
\hline U5930-13-5 & Duster*2//Mq(2)5*G2919K(Sr35)/2*2174 & 0 & $5 \mathrm{R}$ & Sr35 \\
\hline U5931-3-1 & PostRock*2//Mq(2)5*G2919K(Sr35)/2*2174 & 0 & TrR & Sr35 \\
\hline U5932-2-4 & Fuller*2//Mq(2)5*G2919K(Sr35)/2*2174 & $0 / 3+$ & $25 \mathrm{MSS}$ & Sr35 ${ }^{e}$ \\
\hline U5935-2-3 & PostRock*2//P8810-B5B3A2A2 (Sr39+Lr35)/2*2174 & 2 & TrR & Sr39 \\
\hline U5937-4-2 & Duster*2//P8810-B5B3A2A2 (Sr39+Lr35)/2*2174 & $3+/ 2-$ & $\begin{array}{l}10 \mathrm{R} / 35 \mathrm{M} \\
\mathrm{SS}\end{array}$ & $\operatorname{Sr} 39^{e}$ \\
\hline U5938-10-5 & Fuller*2//P8810-B5B3A2A2 (Sr39+Lr35)/2*2174 & $2 / 3+$ & $5 \mathrm{R} / 40 \mathrm{~S}$ & $S r 39^{e}$ \\
\hline U5941-1-6 & Fuller*2//RL6088 (Sr40)/2*2174 & $3+$ & $60 \mathrm{~S}$ & Non-Sr40 \\
\hline U5942-10-1 & PostRock*2//RL6088 (Sr40)/2*2174 & $2 / 3+$ & $\begin{array}{l}30 \mathrm{~S} / 15 \mathrm{M} \\
\mathrm{R}\end{array}$ & Sr40 \\
\hline U5947-1-3 & Duster/3/2174//RL6088 (Sr40)/2*2174 & 2 & 5RMR & Sr40 \\
\hline U5948-11-1 & $2174 * 2 / / \mathrm{Sr} 22 \mathrm{~Tb} / 2 * 2174$ & $12-$ & -- & Sr22 \\
\hline U5950-11-2 & KS05HW14*2/3/CnsSr32As/Lakin//KS05HW14 & $2 / 3+$ & $\begin{array}{l}\text { 5RMR/40 } \\
\mathrm{S}\end{array}$ & Sr32 ${ }^{e}$ \\
\hline U5951-5-2 & KS05HW14*2/3/Mq(2)5*G2919K(Sr35)/Lakin//KS05HW14 & 0 & TrR & Sr35 \\
\hline U5952-5-4 & KS05HW14*2/3/Mq(2)5*G2919K(Sr35)/Lakin//KS05HW14 & $3+$ & $0 / 35 \mathrm{~S}$ & $\operatorname{Sr} 35^{e}$ \\
\hline U5954-1-5 & $\begin{array}{l}\text { KS05HW14*2/3/P8810-B5B3A2A2 } \\
\text { (Sr39+Lr35)/Lakin//KS05HW14 }\end{array}$ & $3+/ 2$ & $0 / 40 \mathrm{~S}$ & Sr39 ${ }^{e}$ \\
\hline
\end{tabular}


${ }^{a}$ Seedling disease rating based on the scale by Stakman et al. (1962), wherein seedlings with low infection type $(<3)$ were considered resistant to race TTKSK and those with a high infection type $(\geq 3)$ were classified as susceptible.

${ }^{\mathrm{b}}$ Adult plant field rating of disease severity assessed using the modified Cobb scale (Peterson et al. 1948) and infection response (Roelfs et al. 1992) rated as R (resistant), MR (moderately resistant), MS (moderately susceptible), or S (susceptible); susceptible check had 80 S rating.

${ }^{c}$ Results for markers for Sr2, Sr22, Sr26, Sr32, Sr35, Sr39, Sr40. Other stem rust resistance genes could be present.

${ }^{\mathrm{d}}$ Data from Jin et al (2007).

${ }^{\mathrm{e}}$ Heterozygous for the stem rust resistance gene based on marker data. 
Table 2. List of primers tested

\begin{tabular}{|c|c|c|c|c|}
\hline $\begin{array}{l}\text { Stem } \\
\text { rust } \\
\text { gene }\end{array}$ & Primer Name & Forward primer* & Reverse primer & Reference \\
\hline Sr22 & Wmc633 & ACACCAGCGGGGATATTTGTTAC & $\begin{array}{l}\text { GTGCACAAGACATGAGGTGGA } \\
\text { TT }\end{array}$ & Olson et al., 2010 \\
\hline Sr22 & csIH81-BM & TTCCATAAGTTCCTACAGTAC & TAGACAAACAAGATTTAGCAC & $\begin{array}{l}\text { Periyannan et al., } \\
2011\end{array}$ \\
\hline Sr22 & csIH81-AG & CTACCTCTGTCAATTTGAAC & GAAAAATGACTGTGATCGC & $\begin{array}{l}\text { Periyannan et al., } \\
2011\end{array}$ \\
\hline Sr22 & Cfa2123 & CGGTCTTTGTTTGCTCTAAACC & ACCGGCCATCTATGATGAAG & Khan et al., 2005 \\
\hline Sr26 & Sr26\#43 & AATCGTCCACATTGGCTTCT & CGCAACAAAATCATGCACTA & Mago et al., 2005 \\
\hline Sr26 & BE518379 & AGCCGCGAAATCTACTTTGA & TTAAACGGACAGAGCACACG & Liu et al., 2010 \\
\hline Sr32 & Stm773 & AAACGCCCCAACCACCTCTCTC & $\begin{array}{l}\text { ATGGTTTGTTGTGTTGTGTGTA } \\
\text { GG }\end{array}$ & $\begin{array}{l}\text { Hayden and Bariana, } \\
\text { unpub; Dundas et al., } \\
2007\end{array}$ \\
\hline Sr32 & Barc55 & $\begin{array}{l}\text { GCGGTCAACACACTCCACTCCTC } \\
\text { TCTC }\end{array}$ & $\begin{array}{l}\text { CGCTGCTCCCATTGCTCGCCGT } \\
\text { TA }\end{array}$ & Yu et al., 2009 \\
\hline Sr35 & Cfa2076 & CGAAAAACCATGATCGACAG & ACCTGTCCAGCTAGCCTCCA & Babiker 2009 \\
\hline Sr35 & Barc51 & $\begin{array}{l}\text { CGCATGAGCAAACAAGCCAACA } \\
\text { ACT }\end{array}$ & $\begin{array}{l}\text { CGGCCACAGCATCGGTTCTCC } \\
\text { AAA }\end{array}$ & Yu et al., 2009 \\
\hline Sr39 & Sr39\#50s & $\begin{array}{l}\text { CCAATGAGGAGATCAAAACAAC } \\
\text { C }\end{array}$ & $\begin{array}{l}\text { TAGCAAGGACCAAGCAATCTT } \\
\text { G }\end{array}$ & Mago et al., 2009 \\
\hline Sr39 & Sr39\#22r & $\begin{array}{l}\text { AGAGAAGATAAGCAGTAAACAT } \\
\text { G }\end{array}$ & $\begin{array}{l}\text { TGCTGTCATGAGAGGAACTCT } \\
\text { G }\end{array}$ & Mago et al., 2009 \\
\hline Sr39 & Rwg27 & GCCTTGGTGGATTTTGTGAT & GCGCTTTCAGTACAGGGTTC & Niu et al., 2011 \\
\hline Sr39 & Rwg28 & AGAGCCTGGGACTGTTGCTA & CAATGGCACTCTTCAAAGCA & Niu et al., 2011 \\
\hline Sr39 & Rwg29 & CGGCTATTGCTCAAAGAAGG & TGTTTCTGTCAGAGGCAACG & Niu et al., 2011 \\
\hline $\begin{array}{l}\text { Sr39 } \\
\text { Sr40 }\end{array}$ & Wmc474 & $\begin{array}{l}\text { ATGCTATTAAACTAGCATGTGTC } \\
\text { G }\end{array}$ & $\begin{array}{l}\text { AGTGGAAACATCATTCCTGGT } \\
\text { A }\end{array}$ & $\begin{array}{l}\text { Bai and St. Amand, } \\
\text { pers. comm.; Wu et } \\
\text { al., } 2009\end{array}$ \\
\hline
\end{tabular}




\begin{tabular}{|c|c|c|c|c|}
\hline $\operatorname{Sr} 40$ & Wmc344 & ATTTCAGTCTAATTAGCGTTGG & $\begin{array}{l}\text { AACAAAGAACATAATTAACCC } \\
\text { C }\end{array}$ & Wu et al., 2009 \\
\hline Sr40 & Wmc661 & CCACCATGGTGCTAATAGTGTC & $\begin{array}{l}\text { AGCTCGTAACGTAATGCAACT } \\
\text { G }\end{array}$ & Wu et al., 2009 \\
\hline Sr40 & Wmc477 & CGTCGAAAACCGTACACTCTCC & $\begin{array}{l}\text { GCGAAACAGAATAGCCCTGAT } \\
\text { G }\end{array}$ & Wu et al., 2009 \\
\hline Sr40 & Gwm374 & ATAGTGTGTTGCATGCTGTGTG & TCTAATTAGCGTTGGCTGCC & Wu et al., 2009 \\
\hline Sr40 & Gwm319 & GGTTGCTGTACAAGTGTTCACG & CGGGTGCTGTGTGTAATGAC & Wu et al., 2009 \\
\hline Sr2 & 3B042G11 & ACAAACACACCGCAAAAAG & TGTCATTGGTGCCTCAGC & McNeil et al., 2008 \\
\hline Sr2 & 3B028F08 & ACGAACAAGGGGAAGACG & TTTCGGTAGTTGGGGATGC & McNeil et al., 2008 \\
\hline Sr2 & $\begin{array}{l}\text { Stm559TGA } \\
\text { G }\end{array}$ & AAGGCGAATCAAACGGAATA & $\begin{array}{l}\text { TGTGTGTGTGTGTGAGAGAGA } \\
\text { G }\end{array}$ & Hayden et al., 2004 \\
\hline \multirow[t]{2}{*}{ Sr2 } & $\operatorname{csSr} 2$ & $\begin{array}{l}\text { CAAGGGTTGCTAGGATTGGAAA } \\
\text { AC }\end{array}$ & $\begin{array}{l}\text { AGATAACTCTTATGATCTTAC } \\
\text { ATTTTTCTG }\end{array}$ & Mago et al., 2011 \\
\hline & csSr2-SNP & AAGCTCTAATTTCTTTGGAATC & & \\
\hline
\end{tabular}

* M13 tail-ACGACGTTGTAAAACGAC added to 5'-end of all forward primers except csSr2. 


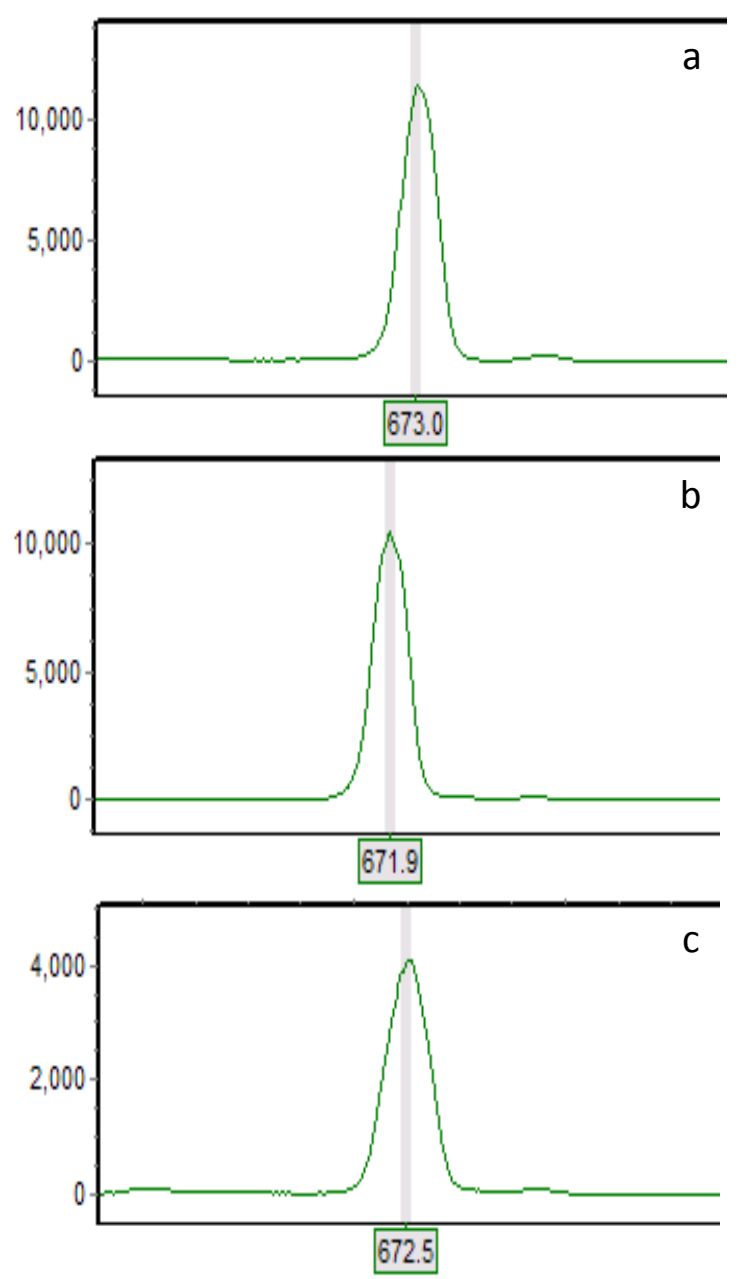

Figure 1. Electropherograms showing the amplification product of Sr39 marker Xrwgs27 in (a) P8810-B5B3A2A2, (b) CnsSr32As, and (c) equal ratio of P8810-B5B3A2A2 and CnsSr32As-k DNA. The $\mathrm{X}$-axis shows the fragment size in base pairs (including an 18bp VIC-dye-labeled M13 primer tail), and the Y-axis represents peak signal intensity in relative fluorescence units. 

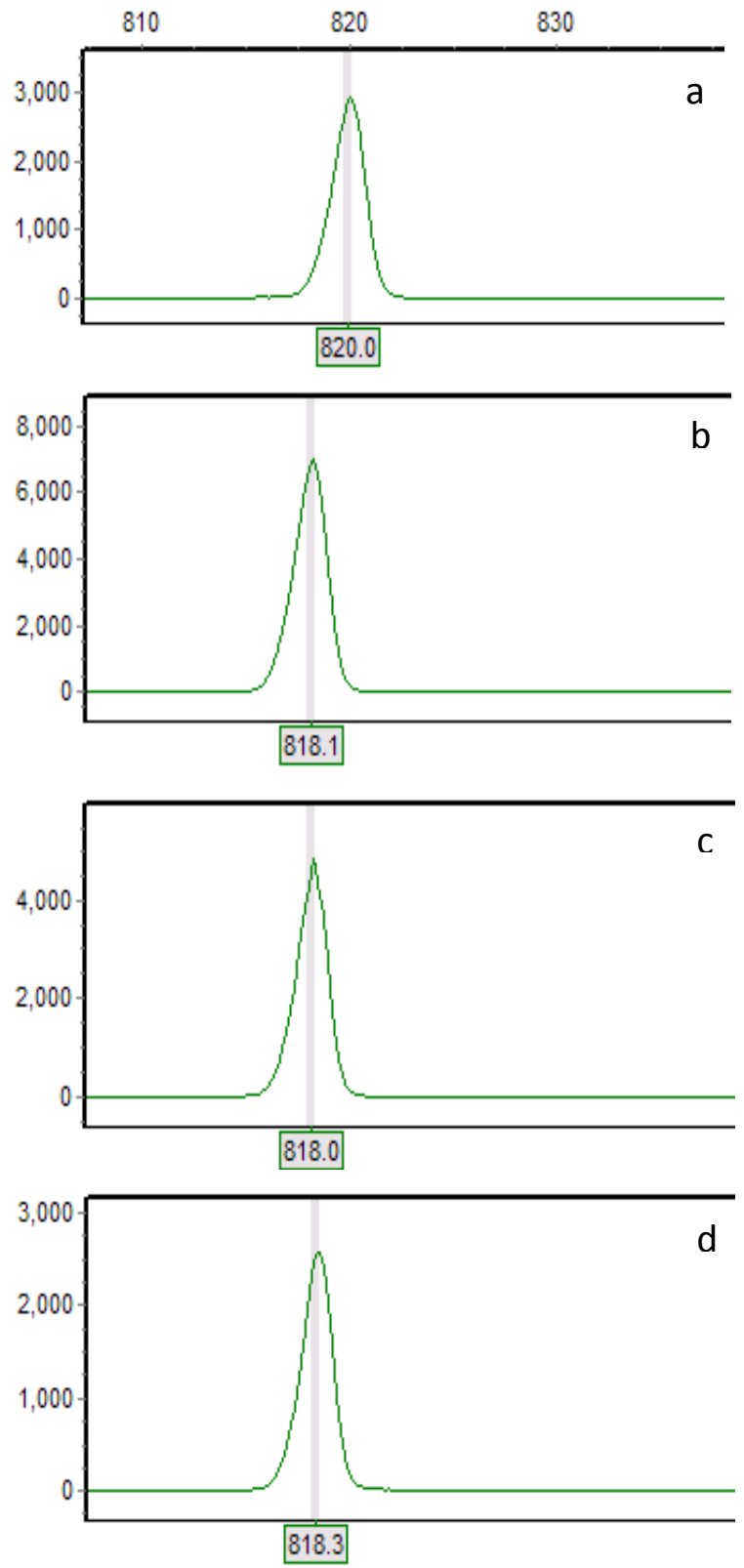

Figure 2. Electropherograms showing the amplification product of marker Xsr39\#22r in (a) RL6088, (b) P8810-B5B3A2A2, (c) RWG1, and (d) CnsSr32As. The X-axis shows the fragment size in base pairs (including an 18bp VIC-dye-labeled M13 primer tail), and the Y-axis represents peak signal intensity in relative fluorescence units. The 820bp fragment in RL6088 is associated with $\mathrm{Sr} 40$ resistance. 

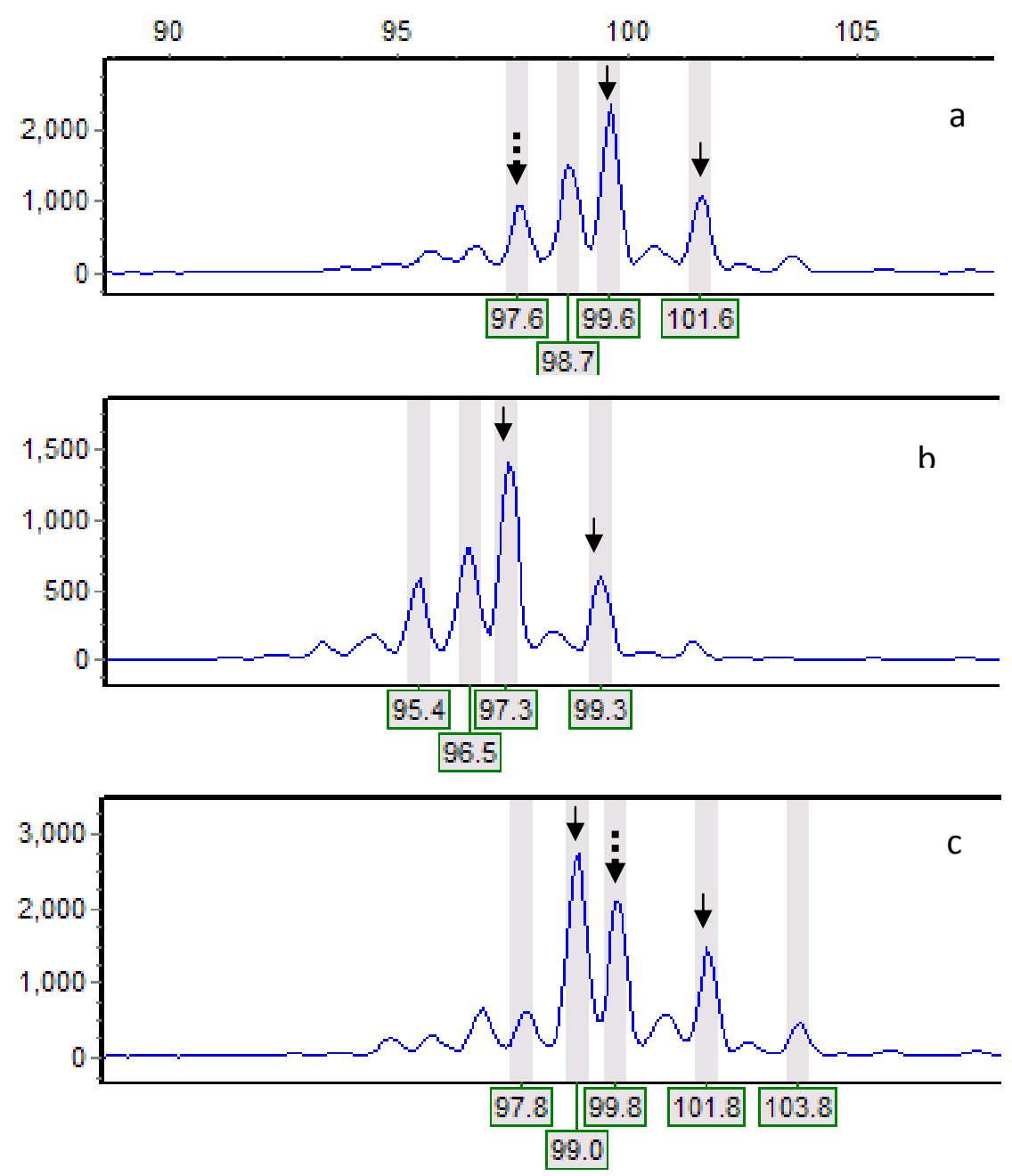

Figure 3. Electropherograms showing the amplification products of marker Xstm559TGAG in Sr2 resistant control CS-Hope DS 3B (a), Sr2 susceptible Billings, PI 646843 (b), and 2174 (c). The $\mathrm{X}$-axis shows the fragment sizes in base pairs (including an 18bp FAM-dye-labeled M13 primer tail), and the $\mathrm{Y}$-axis represents peak signal intensity in relative fluorescence units. The solid arrows indicate the two major peaks in each panel. The broken arrow in (a) points to a stutter peak in CS-Hope DS 3B that is similar in size to the $97.3 \mathrm{bp}$ susceptibility peak in Billings; the one in (c) indicates a plus-A peak that is similar in size to the $99.6 \mathrm{bp}$ peak in the resistant control. The presence of stutter and plus-A peaks complicates data scoring. 